Research Article

\title{
Anthelminthic, Anti-Inflammatory, Antioxidant, and Antimicrobial Activities and FTIR Analyses of Vernonia camporum Stem-Bark
}

\author{
Clement Osei Akoto ${ }^{1},{ }^{1}$ Akwasi Acheampong, ${ }^{1}$ Yaw Duah Boakye, ${ }^{2}$ Bernard Asante, ${ }^{1}$ \\ Samuel Ohene, ${ }^{1}$ and Francis Amankwah ${ }^{2}$ \\ ${ }^{1}$ Department of Chemistry, Faculty of Physical and Computational Sciences, College of Science, \\ Kwame Nkrumah University of Science and Technology (KNUST), Kumasi, Ghana \\ ${ }^{2}$ Department of Pharmaceutics, Faculty of Pharmacy and Pharmaceutical Sciences, KNUST, Kumasi, Ghana
}

Correspondence should be addressed to Clement Osei Akoto; cakoto@hotmail.com

Received 21 April 2021; Accepted 9 September 2021; Published 26 September 2021

Academic Editor: Irene Dini

Copyright (c) 2021 Clement Osei Akoto et al. This is an open access article distributed under the Creative Commons Attribution License, which permits unrestricted use, distribution, and reproduction in any medium, provided the original work is properly cited.

\begin{abstract}
Vernonia camporum is used ethnomedicinally to treat diseases such as malaria, fever, hypertension, mouth sores, pains, inflammation, and skin rashes in Africa. This study aims at investigating the biological activities (anthelminthic, anti-inflammatory, antioxidant, and antimicrobial) and separating some of the biologically active components in the methanol crude extract of the stem-bark of Vernonia camporum. Phytochemical screening, anthelminthic (Lumbricus terrestris (earthworm)), anti-inflammatory (egg albumin denaturation), antioxidant (DPPH and $\mathrm{H}_{2} \mathrm{O}_{2}$ scavenging and total antioxidant capacity (TAC)), and antimicrobial (agar and broth dilution method) assays were performed on the extracts. Column chromatography and FTIR spectroscopic analysis were employed to separate and analyze the least polar constituents of the methanol extract. The preliminary phytochemical analyses revealed the presence of secondary metabolites such as alkaloids, phenols, tannins, saponins, terpenoids, flavonoids, steroids, phytosterols, proteins and amino acids, phlobatannins, glycosides, cardiac glycosides, coumarins, and anthocyanins. The extracts (methanol and hexane) showed a higher concentration-dependent anthelminthic activity. The extracts exhibited high concentration-dependent anti-inflammatory activities with $\mathrm{IC}_{50}$ values of $35.83 \pm 3.984$ and $53.91 \pm 5.8413 \mu \mathrm{g} / \mathrm{mL}$, respectively. The $\mathrm{IC}_{50}$ values for methanol and hexane extracts in the DPPH assay were $17.70 \pm 3.430$ and $29.54 \pm 1.5437 \mu \mathrm{g} / \mathrm{mL}$, and those of the $\mathrm{H}_{2} \mathrm{O}_{2}$ assay were $243.20 \pm 0.1528$ and $352.20 \pm 12.64 \mu \mathrm{g} / \mathrm{mL}$, respectively. TAC results for methanol and hexane extracts were recorded as $31.592 \pm 1.682$ and $30.232 \pm 0.445 \mathrm{gAAE} / 100 \mathrm{~g}$, respectively. The extracts were observed to exhibit antimicrobial activity against test organisms with MICs ranging from 0.1953 to $25.00 \mathrm{mg} / \mathrm{mL}$. Chromatographic separations gave four fractions. FTIR analysis indicated the presence of various functional groups in purified fractions of the methanol extract that confirms the presence of the phytochemicals identified in the screening test. The results indicate that both extracts of V. camporum possess anthelminthic, anti-inflammatory, antioxidant, and antimicrobial activities supporting the traditional usage of this plant.
\end{abstract}

\section{Introduction}

Natural products have enormous applications in the fields of bioorganic, organic synthesis, medicinal, and natural product chemistry, among others [1-3]. The major source of leads for the development of drugs is natural product [3-6]. Statistics on the sources of new drugs from 1981 to 2007 indicate that almost half of the drugs approved since 1994 are based on active metabolites from natural sources
[7-10]. Medicinal plants and human beings have special relationship for centuries [11-13]. Medicinal plants and natural products having pharmacological models have been well thought out as alternative therapy for the treatment of various diseases [14-16]. A significant number of presently used antimalarial, antioxidant, anthelminthic, anti-inflammatory, and antitumor agents are molecules identified and isolated from plants or their synthetic or semisynthetic derivatives [17-19]. 
Vernonia (Asteraceae) is the main genus of the family Vernonieae with almost 1000 species, whilst the family has almost 1500 species and 70 genera, and they are found mostly in the tropical regions $[20,21]$. The genus Vernonia is recognized for having many species serving as food, and others with medicinal and industrial uses. For example, Vernonia amygdalina and Vernonia colorata are consumed as leafy vegetables. Vernonia amygdalina is, possibly, the most used medicinal plant in the genus Vernonia [22-24]. The common and acknowledged medicinal applications include the treatment of schistosomiasis, amoebic dysentery, and gastrointestinal problems. It has been applied in the treatment of malaria, venereal diseases, wounds, hepatitis, and diabetes [25-29]. Species of the genus Vernonia are rich sources of sesquiterpene lactones. This group of compounds has been shown to be insect antifeedant, antifungal, cytotoxic, and antitumoral [30-32]. Numerous sesquiterpene lactones have been identified to be present in Vernonia amygdalina; these include vernolide, vernolepin, vernodalin, and hydroxyvernolide [28, 33-35]. The existence of steroidal saponins and flavonoids has also been documented in this plant [23, 24, 36-40]. Vernonia camporum is a medicinal plant widely used in numerous ethnomedicines in West Africa. In Ghana, it is commonly found in Kwahu-Tafo in the Eastern region and is locally known as Awonyono-ninin. Citizens of this locality boil both the leaves and stem-bark as medication to treat diseases such as malaria, fever, hypertension, mouth sores, pains, inflammation, and skin rashes.

Most research conducted so far has dwelt on the pharmacological potential of the genus Vernonia, including anti-infective, anti-inflammatory, antioxidant, and anticancer [30-32]. At the time of carrying out this research, there were a dearth of scientific reports on the activity of the stem-bark of Vernonia camporum on the above study conditions, except anecdotal reports from local herbalists.

The objective of this experimental research was to determine scientifically the effectiveness of the stem-bark of Vernonia camporum methanol and hexane extracts to act as antioxidant, antimicrobial, anthelminthic, and anti-inflammatory agents using in vitro assays, and, additionally, to separate and identify the presence of the phytochemicals eliciting the biological activities using chromatographic purification and spectroscopic analysis.

\section{Materials and Methods}

2.1. Sample Collection, Identification, and Authentication. The stem-barks of Vernonia camporum were collected from a farm land in Kwahu-Tafo, in the Kwahu East District of Eastern Region of Ghana (latitude: $6^{\circ} 39^{\prime} 26.5^{\prime \prime} \mathrm{N}$ and longitude: $0^{\circ} 39^{\prime} 44.9^{\prime \prime} \mathrm{W}$ ) with the help of a local herbalist on September 13, 2019. The plants were taxonomically identified and authenticated by Mr. Clifford Osafo Asare at the Department of Herbal Medicine, Faculty of Pharmacy and Pharmaceutical Sciences, Kwame Nkrumah University of Science and Technology (KNUST), where a voucher specimen with reference number (KNUST/8M1/2020/S001) was deposited in the herbarium for reference purposes.
2.2. Chemicals and Reagents. All chemicals were purchased from Sigma Aldrich Co. Ltd, Irvine, UK, except the standard drugs. The organic solvents were of analytical grade and procured from BDH Laboratory Supplies (England).

2.3. Preparation of Plant Material. The stem-barks of $V$. camporum were chopped into small pieces, thoroughly washed, first under running water to remove any form of debris, and subsequently rinsed in distilled water to exclude heavy metals in tap water and air-dried under shade for two weeks. The dried material was coarsely milled using a pulverizer machine and stored in a desiccator until analysis [41].

2.3.1. Extraction of Methanol and Hexane Plant Materials. A mass of $250 \mathrm{~g}$ of the powdered stem-bark sample of $V$. camporum was soaked separately in $1 \mathrm{dm}^{3}$ of methanol and hexane and extracted using maceration over 72 hours, following a method previously described by Osei Akoto et al. [41]. The methanol and hexane extracts were condensed and evaporated to dryness using the rotary evaporator at $50^{\circ} \mathrm{C}$ (BUCHI Rota vapor R-114). The extracts were dried in an oven at $40^{\circ} \mathrm{C}$, and the percentage yield of extracts with respect to powdered plant material was determined. The extracts were then stored at $4^{\circ} \mathrm{C}$ in a refrigerator.

\subsection{Phytochemical Screening of Extracts and Pulverized} Sample. The pulverized sample and the crude extracts (methanol and hexane) obtained from the stem-bark of $V$. camporum were screened to assess the presence of phytoconstituents using the methods described by Trease and Evans [42].

\subsection{In Vitro Anti-Inflammatory Assay Using Egg Albumin} Denaturation. Anti-inflammatory assay was carried out on the extracts of $V$. camporum according to the methods described by Sree Kumari et al. [43] and slightly modified by Osei Akoto, et al. [41]. The egg denaturation assay was employed in this study, as anti-inflammatory agents have been reported to inhibit thermal denaturation of proteins [43]. The reaction mixtures of total volume $5 \mathrm{~mL}$ were prepared by dissolving $0.2 \mathrm{~mL}$ of egg albumin (fresh egg of a hen), $2.8 \mathrm{~mL}$ of phosphate-buffered saline (PBS, $\mathrm{pH}$ of 6.4), and $2 \mathrm{~mL}$ of the various concentrations of extract $(100,50$, 25 , and $12.5 \mu \mathrm{g} / \mathrm{mL})$. Diclofenac sodium $(100,50,25$ and $12.5 \mu \mathrm{g} / \mathrm{mL}$ ) was used as the standard drug. A volume of $2 \mathrm{~mL}$ of doubled distilled water solution served as negative control. The mixtures were incubated at $37^{\circ} \mathrm{C}$ in a BioOxygen Demand (BOD) incubator for 15 minutes. The mixtures were then heated in a water bath at $70^{\circ} \mathrm{C}$ for 5 minutes to induce denaturation. The absorbance of the solutions was measured in triplicate at $660 \mathrm{~nm}$ using UV-Vis spectrophotometer. The procedure was independently repeated to obtain three independent sets of data for the analysis in triplicate. The percentage inhibition of protein denaturation was calculated as follows: 


$$
\% \text { inhibition }=\frac{A_{o}-A}{A_{o}} \times 100 \text {, }
$$

where $A_{o}=$ absorbance of the negative control and $A=$ absorbance of the test solution.

2.6. Collection of Lumbricus terrestris for Anthelminthic Activity. Lumbricus terrestris (Earthworms) were collected from a water-logged area behind the Department of Theoretical and Applied Biology within KNUST, KumasiGhana (latitude $6^{\circ} 35 \mathrm{~N}-6^{\circ} 40 \mathrm{~N}$ and longitude $1^{\circ} 30 \mathrm{~W}-1^{\circ} 35$ $\mathrm{W})$. The worm type was authenticated at the Zoology Unit, Department of Theoretical and Applied Biology, KNUST by Mr. Lawrence Yeboah.

2.6.1. In Vitro Anthelminthic Assay. In vitro anthelmintic activity of both methanol and hexane extracts against Lumbricus terrestris (earthworms) was examined. The anthelmintic assay was carried out using the methods previously described by Ajaiyeoba et al. [44] and slightly modified by Osei Akoto et al. [41]. Stock solutions of $8.0 \mathrm{mg} / \mathrm{mL}$ of extracts and albendazole (reference drug) were prepared using sterile distilled water as a solvent. From the stock solution, four concentrations of $4.0,2.0,1.0$, and $0.5 \mathrm{mg} / \mathrm{mL}$ were prepared. Double distilled water was used as a negative control. All the test solutions including the standard reference drug were freshly prepared before the start of the experiment. Three worms of approximately the same size and length were released into separate Petri dishes containing $50 \mathrm{~mL}$ each of the various test solutions. Time of paralysis and time of death of the worms were determined and recorded. Time of paralysis was noted when no movement of any sort could be observed except when the worms were shaken vigorously. Time of death of worms was recorded after ascertaining that the worms neither moved when shaken vigorously nor moved when dipped in warm water $\left(50^{\circ} \mathrm{C}\right)$ followed by fading away of their body colors. The experiment was independently repeated to obtain three independent sets of data for the analysis, and the results are expressed as a mean \pm standard error of the mean (SEM) $(N=3)$.

2.7. In Vitro Antioxidant Assays. Three main assays were used in the determination of the antioxidant activity of the plant extract. They were 1,1-diphenyl-2-picryl-hydrazyl (DPPH) free radicals scavenging, hydrogen peroxide scavenging, and the Total Antioxidant Capacity assays.

2.7.1. DPPH Radical Scavenging Assay. The free radical scavenging activity of the extracts of $V$. camporum was examined according to the methods previously described by Sanchez-Moreno et al. [45] and slightly modified by Osei Akoto et al. [1]. Ascorbic acid was used as reference standard. The absorbances were measured at $517 \mathrm{~nm}$. The experiment was independently repeated to obtain three independent sets of data for the analysis. DPPH radical scavenging (\%) was calculated using the formula

$$
\% \text { scavenging }=\frac{A_{o}-A}{A_{o}} \times 100,
$$

where $A_{o}=$ absorbance of control and $A=$ absorbance of test solution.

2.7.2. Hydrogen Peroxide Scavenging Assay. Hydrogen peroxide scavenging activity of the extracts of $V$. camporum was examined according to the methods reported by Mukhopadhyay et al. [46] and slightly modified by Osei Akoto et al. [17]. The assay is based on precise complex formation of ferrous ion with 1,10-phenanthroline to form red-orange tri-phenanthroline complex. Gallic acid was used as reference standard. Absorbance was taken at $510 \mathrm{~nm}$ using a UV-vis spectrophotometer. The negative control contained only ferrous ammonium sulphate $(0.5 \mathrm{~mL}, 1 \mathrm{mM})$, distilled water $(3 \mathrm{~mL})$, and 1,10-phenanthroline $(3 \mathrm{~mL}, 1 \mathrm{mM})$. The experiment was independently repeated to obtain three independent sets of data for the analysis. The percentage scavenging activity of the extracts was calculated using the following formula:

$$
\% \text { scavenging }=\frac{\text { Atest }}{\text { Acontrol }} \times 100 \text {, }
$$

where Atest is the absorbance of the test samples, and Acontrol is the absorbance of the negative control. The results were further reported in $\mathrm{IC}_{50}$.

2.7.3. Total Antioxidant Capacity (TAC) Assay. A modification of the method described by Prieto et al. [47], as previously described by Osei Akoto et al. [17], was used to study the total antioxidant capacity of the extracts of $V$. camporum. The method is based on the reduction of phosphomolybdic acid [Mo (VI)] to phosphomolybdenum [Mo (V), a blue complex] by the extracts and reference standard. Ascorbic acid was used as the reference standard, and distilled water was used as the blank. The absorbance of the solutions was measured in triplicate, using the UVvisible spectrophotometer at $695 \mathrm{~nm}$. The experiment was independently repeated to obtain three independent sets of data for the analysis. From the linear equation of the ascorbic acid concentration-absorbance plot (standard curve), the corresponding independent variables as ascorbic acid equivalents (AAE) were determined, and the results were expressed as $\mathrm{gAAE} / 100 \mathrm{~g}$ ascorbic acid.

2.8. In Vitro Antimicrobial Assay. Agar well diffusion and Broth microdilution assays were employed to assess the antimicrobial property of the extracts of $V$. camporum. The Agar well diffusion method was employed to evaluate the susceptibility of the microbes to the extracts. The Broth microdilution method was used to determine the minimum concentration required to inhibit each of the microbes employed for the experiment.

2.8.1. Sources of Microorganisms. Four types of bacteria strains and one clinical strain fungus were used as test 
organisms. These were two Gram positive bacteria, which included Staphylococcus aureus (ATCC 25923) and Enterococcus faecalis (ATCC 29212), and two Gram negative bacteria, which included Escherichia coli (ATCC 25922) and Pseudomonas aeruginosa (ATCC 4853). The fungus was Candida albicans, a clinical strain.

These microbial strains were obtained from the stocks kept by the Microbiology Laboratory of the Department of Pharmaceutics, Faculty of Pharmacy and Pharmaceutical Science, KNUST, Kumasi. The microbial strains were subcultured on nutrient agar slants and incubated at $37^{\circ} \mathrm{C}$ for 24 hours.

2.8.2. Inoculum Preparation. The test organisms were prepared by growing them on separate nutrient agar (Oxoid, United Kingdom) plates for $18-24$ hours at $37^{\circ} \mathrm{C}$ in an incubator. Using the direct colony suspension method, suspensions of colonies were transferred from the plates with sterile inoculating loop into $10 \mathrm{~mL}$ of sterile saline in test tubes. Their turbidities were adjusted and compared to the $0.5 \mathrm{McF}$ arland standard and read with the eye $[48,49]$.

2.8.3. Agar Well Diffusion Method. The antimicrobial activities of the extracts of $V$. camporum were determined using the agar well diffusion method previously described by Konning et al. [50] and slightly modified by Osei Akoto et al. [49]. The nutrient agar (Oxoid, United Kingdom) plates were formed by inoculating $100 \mu \mathrm{L}$ of the test organisms with micropipette and sterile pipette tips using the pour plate method. By means of sterile cork borer, 4 wells $(10 \mathrm{~mm}$ in diameter) were made in the agar and filled with $200 \mu \mathrm{L}$ of the extracts $(6.25,12.5$, and $25.0 \mathrm{mg} / \mathrm{mL})$ and reference drugs $(0.05 \mathrm{mg} / \mathrm{mL})$ concentrations. Three replicates of the experiment for the extracts and reference drugs were done, and the plates incubated at $37^{\circ} \mathrm{C}$ for 24 hours. The diameter of zone of growth-inhibition produced was measured, and the mean values were calculated. Ciprofloxacin and clotrimazole were used as the standard reference antimicrobial drugs.

2.8.4. Broth Microdilution. In the determination of minimum inhibitory concentration (MIC), the micro-well dilution method previously described by Konning et al. [50] and slightly modified by Osei Akoto et al. [49] was used. Eight different concentrations of the extracts were prepared serially in sterile distilled water in the range of $(0.1953 \mathrm{mg} /$ $\mathrm{mL}$ to $25.0 \mathrm{mg} / \mathrm{mL}$ ), whereas ciprofloxacin and clotrimazole concentrations were prepared with the same method ranging from $(0.00004883 \mathrm{mg} / \mathrm{mL}$ to $0.00625 \mathrm{mg} /$ $\mathrm{mL})$. The assays were made in 96 -well microplates to a total volume of $250 \mu \mathrm{L}$. The plates were filled with $125 \mu \mathrm{L}$ double strength nutrient broth, followed by extract, ciprofloxacin, and clotrimazole solutions of $100 \mu \mathrm{L}$, and then, $25 \mu \mathrm{L}$ suspensions of the test organisms was finally added. The experiment was independently repeated in three replicates and incubated at $37^{\circ} \mathrm{C}$ for 24 hours, and the microbial growth was determined after addition of $20 \mu \mathrm{L}$ of $0.2 \mathrm{mg} /$
mL MTT (Sigma-Aldrich, St. Louis, MO. USA). The development of purple coloration after 30-minute addition of the MTT indicates microbial growth, when no color is the resultant of inhibition.

2.9. Thin Layer Chromatography (TLC). The number of phytoconstituents present in the extracts was determined by the analytical TLC method. The precoated silica gel plates $(0.25 \mathrm{~mm})$ with a fluorescent indicator (F254) were spotted with the methanol and hexane extracts of $V$. camporum about $1 \mathrm{~cm}$ from the bottom edge of plates, with the aid of capillary tubes, and allowed to dry as previously described [1]. The ratios of $1: 9$ and $1: 4$ (ethyl acetate/hexane) gave the best separation of the least polar components for all the extracts. The plates were dried and visualized with a 254/365 nm UV lamp. The separated spots were then pencilmarked, and their sample and solvent fronts were measured. The retardation factor $\left(R_{f}\right)$ of the eluted spots was calculated as follows:

$$
R_{f}=\frac{\text { distance travelled by the spot }}{\text { distance travelled by the solvent front }} .
$$

This solvent system was then adapted and used in column chromatographic separation.

2.10. Column Chromatographic Separation. Flash chromatography was performed using $40-63 \mu \mathrm{m}$ silica gel $(200 \times 400$ mesh) to separate the number of components present in the extracts as previously described [1]. A mass of $1 \mathrm{~g}$ of dry powdered methanolic extract was chromatographed on a column packed with silica gel and eluted with a gradient of solvents, ethyl acetate/hexane $(5: 45 ; 10: 40,50 \mathrm{~mL}$ each) to provide 4 fractions, namely, A to $\mathrm{D}$. The fractions were monitored by means of TLC (eluent, ethyl acetate/hexane 1:9 and $1: 4)$. The fractions were evaporated to dryness using the rotary evaporator, then dried, and stored at $4^{\circ} \mathrm{C}$ in a refrigerator until their use.

2.11. Fourier-Transform Infrared Spectroscopy (FTIR) Analysis. The separated fractions (A-D) were subjected to (FTIR) analysis (UATR Two, PerkinElmer) to determine the functional groups present. The regions between $4000 \mathrm{~cm}^{-1}$ and $400 \mathrm{~cm}^{-1}$ were scanned, then followed by baseline correction.

2.12. Data Analysis. Microsoft Excel 2019 and GraphPad Prism 5.0 for Windows (GraphPad Software, San Diego, CA, USA) were used for all data analyses and graphs.

\section{Results and Discussion}

3.1. Extraction of Plant Material. The yields of the extract of $V$. camporum in relation to the powdered plant material were calculated as percentages. The yields were 6.32 and $0.20 \%$ for methanol and hexane extracts, respectively. 
3.2. Phytochemical Screening. The therapeutic activities of plants are due to the presence of complex chemical constituents in different parts [49]. Phytochemical screening of $V$. camporum revealed the presence of all fourteen secondary metabolites tested for both the pulverized sample and the methanol extract, except proteins and amino acids that were absent in the methanol extract. However, alkaloids, phenols, flavonoids, phlobatannins, and coumarins were absent in the hexane extract (Table 1).

The methanol and hexane extracts had nine phytochemicals in common, that is, tannins, saponins, terpenoids, steroids, phytosterols, glycosides, cardiac glycosides, and anthocyanins. Phytochemicals such as alkaloids, flavonoids, tannins, saponins, steroids, terpenoids, and glycosides had been identified in many species of Vernonia [51-59]. These phytochemicals present in the Vernonia species are known to exhibit a wide array of pharmacological activities such as antitumoral, antimicrobial, antioxidant, antidiabetic, anti-inflammatory, anthelminthic, analgesics, antimalarial, and many others $[34,52,58,60-62]$. Alkaloids and sesquiterpene lactones isolated from Vernonia amygdalina are in clinical studies due to its pharmacological importance [33, 63]. Sesquiterpene lactones such as vernodalin, vernolepin, and vernomygdin had been isolated from Vernonia amygdalina and shown to exhibit hepatoprotective activity, antioxidant activity, and other biological activities $[33,64]$. The presence of these various phytochemicals in the sample of the stem-bark of $V$. camporum could be responsible for its traditional therapeutic benefits.

\subsection{In Vitro Anti-Inflammatory Assay (Egg Albumen Dena-} turation Method). Erythrocyte membranes are known and reported to have some structural and biological similarities with lysosomal membranes and, hence, considered analogues to each other [43]. Therefore, the ability of medicinal plant extracts to stabilize the denaturation of red blood cells demonstrates significant property in stabilizing or inhibiting lysosomal enzymes. Since erythrocytes are basically proteins of hemoglobin, stabilization or inhibition of protein denaturation such as egg albumin denaturation by medicinal plant extracts provides evidence of red blood cells stabilization and hence lysosomal enzyme inhibition. Methanol and hexane extracts and diclofenac sodium (standard drug) displayed concentration dependent anti-inflammatory activity at test concentrations of 12.5 to $200 \mu \mathrm{g} / \mathrm{mL}$ (Figure 1). However, the anti-inflammatory activity of diclofenac was significantly $(P<0.001)$ higher than those of the extracts. Additionally, the methanol extract showed better activity compared to the hexane extract at all test concentrations (Figure 1) with $\mathrm{IC}_{50}$ values of $35.83 \pm 0.1343$ and $53.91 \pm 0.1528 \mu \mathrm{g} /$ $\mathrm{mL}$, respectively (Table 2 ).

The results implied that the effectiveness of the test samples of extracts as anti-inflammatory agents was higher in the methanol extract compared to the hexane extract (Figure 1). The inflammatory activity of the extracts can be attributed to the presence of steroids, phenols, tannins, saponins, terpenoids, flavonoids, and alkaloids present in $V$. camporum, which have been reported to exhibit antiinflammatory activity $[17,65]$. Therefore, the anti-inflammatory activity of the extracts exhibited by the egg albumin denaturation method may support the ethnomedicinal use of boiling both the leaves and stem-bark of $V$. camporum as medication to treat mouth sores, pains, wounds, skin rashes, and boils.

3.4. Anthelminthic Activity. Anthelmintic potential of the stem-bark extracts of $V$. camporum was examined using earthworms (i.e., Lumbricus terrestris), due to their physiological and anatomical resemblance with that of intestinal roundworm parasites of human beings as well as their ease of availability $[41,66]$. Methanol and hexane extracts and albendazole (standard drug) displayed concentration-dependent anthelmintic activity at test concentrations of 0.5 to $8.0 \mathrm{mg} / \mathrm{mL}$ as shown in Figures 2 and 3 . The anthelmintic activities of methanol and hexane extracts at test concentrations were observed to be significantly $(P<0.001)$ higher compared to albendazole-treated worms. The worms in the negative control (double distilled water) were alive after 24 hours.

The mode of action of some anthelmintics like imidazothiazoles, derquantel, and piperazine is to cause paralysis of worms, such that they can be expelled in the faeces of man and animals [41]. The extracts did not only exhibit such potency, but also cause both paralysis and death of the Lumbricus terrestris worms at a rate much higher than the standard drug albendazole. The methanol extract showed higher anthelminthic potency than the hexane extract in both paralysis and death time of the worms. The absence of alkaloids in the hexane extract, which is known to be potent anthelmintics, could explain the methanol extract higher potency, though both contain phytochemicals such as saponins, tannins, and terpenoids [1]. The results revealed that the stem-bark of $V$. camporum possesses potentially effective anthelminthic agents, and hence, further studies into the compounds responsible for the pharmacological activity are warranted.

3.5. In Vitro Antioxidant Activity. The total antioxidant potential of a plant extract depends largely on both the constituent of the extract and the test system [41]. Techniques employed in the assessment of antioxidant activity differ from one another in terms of assay principles, mechanisms involved, and experimental conditions [47]. Different factors can influence the activity of the extract due to their multifunctionalities; hence, more than one assay needs to be performed to evaluate the various modes of antioxidant actions. This is because a single method is not sufficient to estimate the antioxidant capacity [49]. Considering the various mechanisms of antioxidant actions, the antioxidant properties of the extracts were evaluated by (DPPH) free radicals scavenging, hydrogen peroxide scavenging, and the total antioxidant capacity assays [41]. 
TABle 1: Phytochemical constituents of the pulverized sample and extracts of V. camporum.

\begin{tabular}{lccc}
\hline Phytochemical & Pulverized sample & Methanol extract & Hexane extract \\
\hline Alkaloids & + & + & - \\
Phenols & + & + & - \\
Tannins & + & + & + \\
Saponins & + & + & + \\
Terpenoids & + & + & + \\
Flavonoids & + & + & + \\
Steroids & + & + & + \\
Phytosterols & + & + & + \\
Proteins and amino acids & + & + & + \\
Phlobatannins & + & + & + \\
Glycosides & + & + & + \\
Cardiac glycosides & + & + & + \\
Coumarins & + & + & + \\
Anthocyanins & + & + & + \\
\hline
\end{tabular}

$(+)=$ presence of the secondary metabolite; $(-)=$ absence of the secondary metabolite.

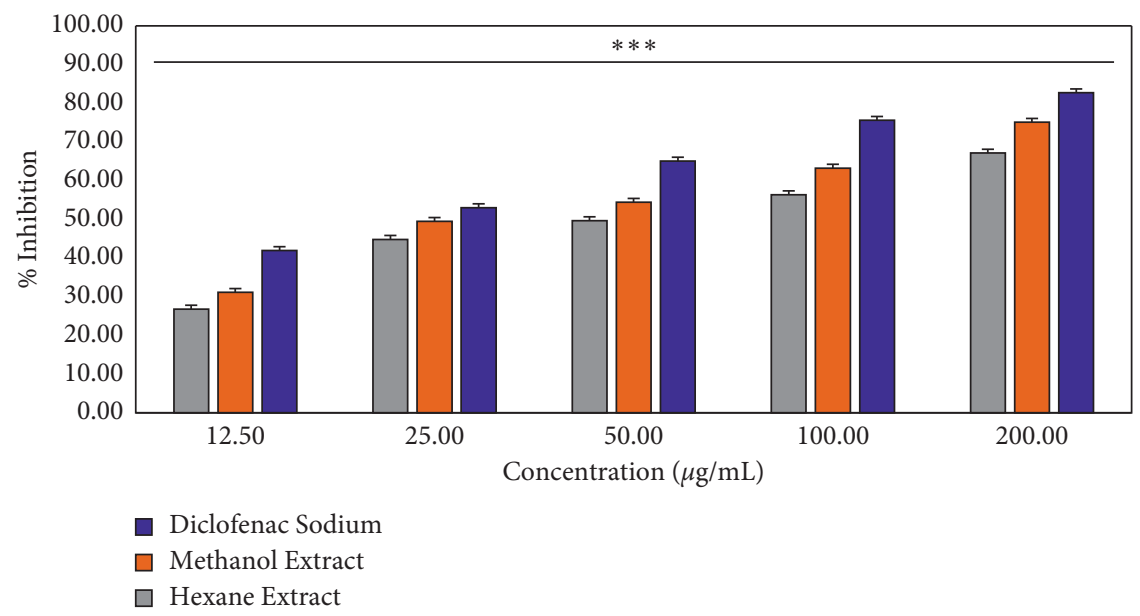

FIgURE 1: Percentage in vitro anti-inflammatory action of methanol and hexane extracts of $V$. camporum. Results were expressed as mean $\pm \operatorname{SEM}(N=3) ;{ }^{* * *} P<0.001$ compared to diclofenac sodium (reference drug) using one-way ANOVA.

TABLE 2: $\mathrm{IC}_{50}$ of anti-inflammatory activity of extracts of V. camporum.

\begin{tabular}{ll}
\hline Sample & $\mathrm{IC}_{50}(\mu \mathrm{g} / \mathrm{mL})$ \\
\hline Standard (diclofenac sodium) & $20.38 \pm 0.2080$ \\
Methanol & $35.83 \pm 0.1343$ \\
Hexane & $53.91 \pm 0.1528$ \\
\hline
\end{tabular}

3.5.1. DPPH Radical Scavenging Capacity. DPPH scavenging activity of the extracts was used to determine and study the ability of the methanol and hexane extracts of stem-bark of $V$. camporum to mop up free radicals that may be found in animals and humans. Methanol and hexane extracts of $V$. camporum and ascorbic acid (reference standard) scavenged DPPH at concentrations ranging between $6.25 \mu \mathrm{g} / \mathrm{mL}$ to $100 \mu \mathrm{g} / \mathrm{mL}$ as shown in Figure 4 .

The reference antioxidant (ascorbic acid), methanol, and hexane extracts of $V$. camporum showed varying antioxidant activity in the DPPH free radical scavenging assay with $\mathrm{IC}_{50}$ ranging from $7.283 \pm 0.0938$ to $29.540 \pm 1.5437 \mu \mathrm{g} / \mathrm{mL}$, as shown in Table 3.
The results implied that the effectiveness of the test samples of extracts as antioxidants has methanol extract higher than hexane extract (Figure 4). The methanol extract exhibiting a better radical scavenging activity than the hexane extract might be attributed to the presence of additional phytochemicals like flavonoids, phlobatannins, and phenols, which are absent in the hexane extract. The scavenging activity of the extracts can be attributed to the presence of tannins, flavonoids, phenols, phlobatannins, and terpenoids $[19,67]$. The DPPH scavenging results show that extracts of the stem-bark of $V$. camporum may be useful in the manufacture of drugs to help prevent or cure health problems that could arise from the systemic actions of oxidative agents.

3.5.2. Hydrogen Peroxide $\left(\mathrm{H}_{2} \mathrm{O}_{2}\right)$ Radical Scavenging Assay. The scavenging activity of $\mathrm{H}_{2} \mathrm{O}_{2}$ molecules by extracts determines the strength of the extracts towards scavenging $\mathrm{H}_{2} \mathrm{O}_{2}$ and hence its ability to inhibit lipid peroxidation reactions [68]. Hydrogen peroxide radical scavenging potential of the methanol and hexane extracts of $V$. camporum 


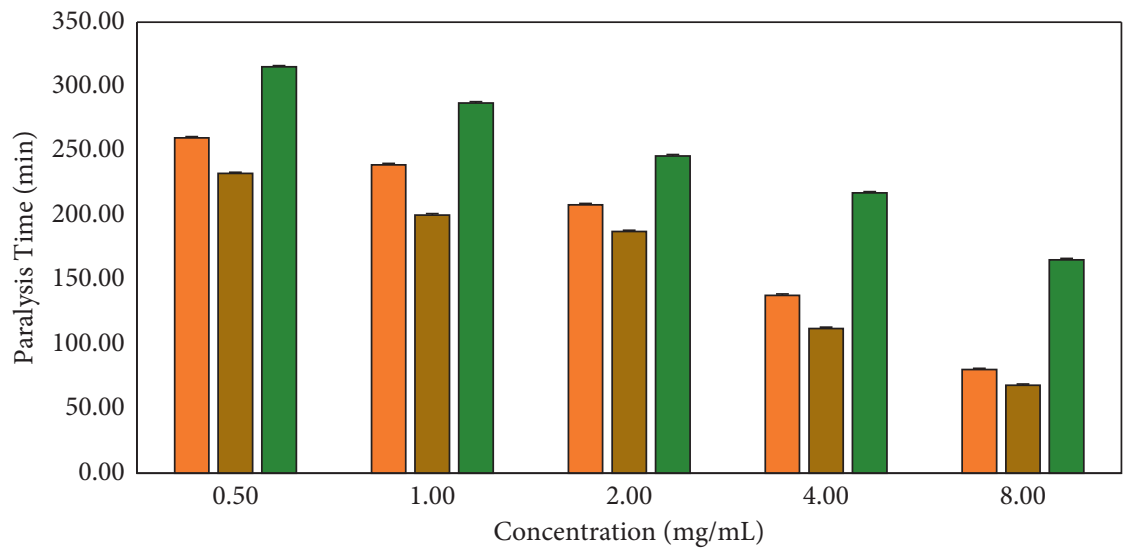

Albendazole

$\square$ Methanol Extract

$\square$ Hexane Extract

Figure 2: Anthelmintic activity of the extracts of $V$. camporum and albendazole. Each time represents mean $\pm \operatorname{SEM}(N=3)$; ${ }^{* * *} P<0.001$ compared to the albendazole treatment using one-way ANOVA.

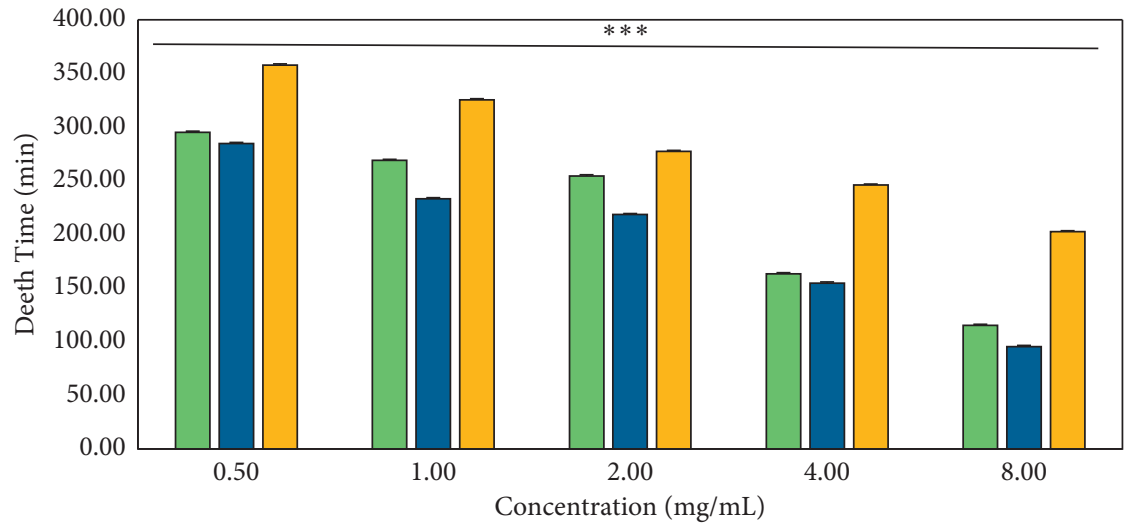

$\square$ Albendazole

- Methanol Extract

$\square$ Hexane Extract

Figure 3: Anthelmintic activity of the extracts of $V$. camporum and albendazole. Each time represents mean $\pm \operatorname{SEM}(N=3)$; ${ }^{* * *} P<0.001$ compared to the albendazole treatment using one-way ANOVA.

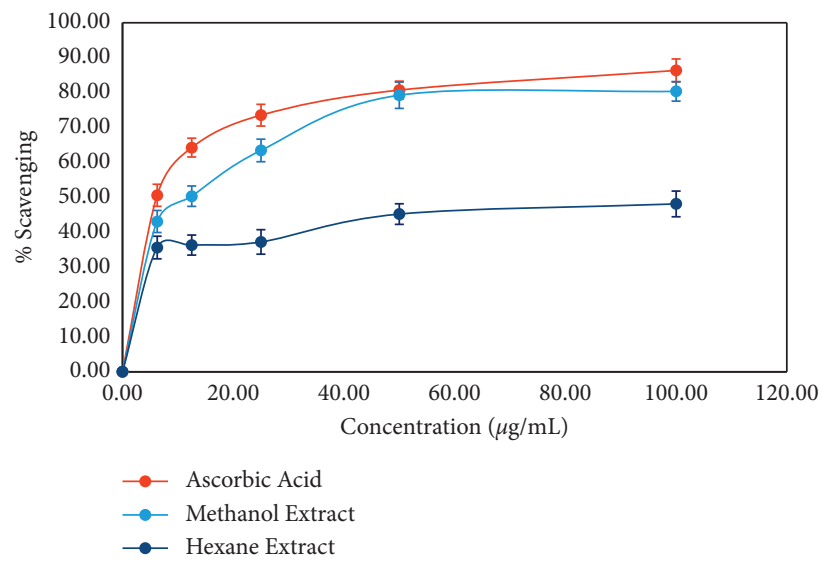

FIGURE 4: Comparative DPPH radical scavenging activity of the extracts of V. camporum and ascorbic acid. 
TABLE 3: $\mathrm{IC}_{50}$ of DPPH radical scavenging activity for the methanol and hexane extracts of $V$. camporum and ascorbic acid.

\begin{tabular}{lc}
\hline Sample & $\mathrm{IC}_{50}(\mu \mathrm{g} / \mathrm{mL})$ \\
\hline Standard (ascorbic acid) & $7.283 \pm 0.0938$ \\
Methanol extract & $17.700 \pm 3.3430$ \\
Hexane extract & $29.540 \pm 1.5437$ \\
\hline
\end{tabular}

was evaluated by using hydrogen peroxide $\left(\mathrm{H}_{2} \mathrm{O}_{2}\right)$ scavenging method with gallic acid as a reference standard. The results are shown in Figure 5.

The results were represented in $\mathrm{IC}_{50}(\mu \mathrm{g} / \mathrm{mL})$ to examine the amount of the test solution that is able to scavenge $50 \%$ of the $\mathrm{H}_{2} \mathrm{O}_{2}$. Results showed that both methanol and hexane extracts of $V$. camporum demonstrated a significant antioxidant activity in concentration dependent manner. The $\mathrm{IC}_{50}$ values ranged from $169.00 \pm 0.1528$ to $352.20 \pm 12.640 \mu \mathrm{g} / \mathrm{mL}$ as shown in Table 4.

From the results, methanol extract was a more effective antioxidant than hexane extract, which presumably could be attributed to the absence of phytochemicals like flavonoids, phlobatannins, and phenols in the latter, although they are all good antioxidants. From this study, the bioactive isolates from these extracts responsible for antioxidant activity could be attributed to the presence of tannins, flavonoids, phenols, phlobatannins, and terpenoids in the stem-bark of $V$. camporum and could be exploited for the treatment of diseases associated with oxidative-stress.

3.5.3. Total Antioxidant Capacity (TAC). Ascorbic acid (vitamin C) is a natural organic compound possessing significant antioxidant abilities, and it is normally found in both plants and animals. It is a water-soluble antioxidant known to aid in tyrosine, folic acid, and tryptophan metabolism [69]. It is reported to metabolize cholesterol, thereby increasing its elimination and resulting in low blood cholesterol. It is widely established to contribute significantly to the synthesis of amino acid carnitine and the catecholamines that regulate the nervous system. It aids in the absorption of iron and breaking down of histamine. It can function as a redox buffer, which aids in the reduction of and hence neutralizing reactive species of oxygen. The outlined metabolic processes of ascorbic acid involve all the multiple mechanisms of antioxidants [70] and hence are widely used as the reference standard for numerous antioxidant evaluation assays including this assay.

Concentrations of ascorbic acid ranging between 6.25 and $100 \mu \mathrm{g} / \mathrm{mL}$ showed antioxidant activity and mean absorbances between $0.3140 \pm 0.0142$ to $0.9097 \pm 0.240$ at a wavelength of $695 \mathrm{~nm}$ (Figure 6).

The TAC was found to be proportional to the concentration of extract. The extracts of stem-bark of V. camporum exhibited a significant increase in TAC expressed as ascorbic acid equivalent. TAC of the extracts was examined by the phosphomolybdenum method, and the results were expressed as gram ascorbic acid equivalent per 100 grams $(\mathrm{gAAE} / 100 \mathrm{~g})$. The gAAE/100 $\mathrm{g}$ represents the fraction of the

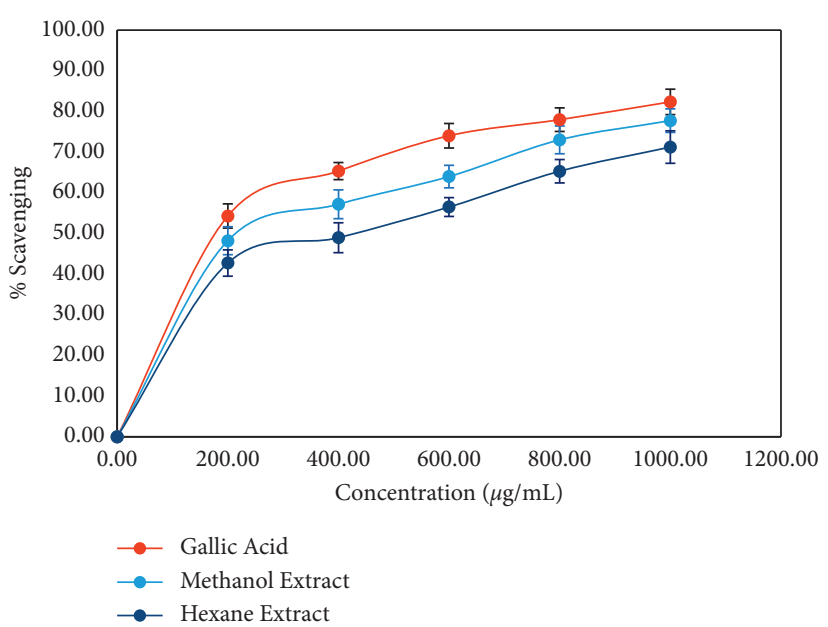

FIGURE 5: Hydrogen peroxide radical scavenging capacity of the extracts of $V$. camporum and gallic acid.

TABLE 4: IC $_{50}$ of hydrogen peroxide radical scavenging activity of extracts of $V$. camporum.

\begin{tabular}{lc}
\hline Sample & $\mathrm{IC}_{50}(\mu \mathrm{g} / \mathrm{mL})$ \\
\hline Standard (gallic acid) & $169.00 \pm 0.1528$ \\
Methanol extract & $243.20 \pm 0.1528$ \\
Hexane extract & $352.20 \pm 12.640$ \\
\hline
\end{tabular}

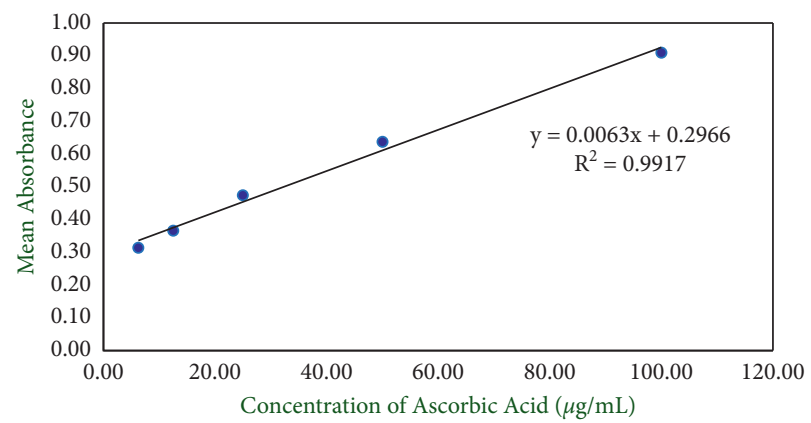

Figure 6: Mean absorbance of $\mathrm{PMo}_{4}{ }_{4} \mathrm{Mo}^{\mathrm{VI}}{ }_{8} \mathrm{O}_{40}{ }^{7-}$ (formed in ascorbic acid solution) against the concentration of ascorbic acid solution.

plant extract that can act as ascorbic acid in $100 \mathrm{~g}$ of the extract. The methanol and hexane extracts had $31.592 \pm 1.682$ and $30.232 \pm 0.445$ gAAE $/ 100$ g, respectively (Table 5). This simply means that 31.592 of methanol extract and 30.232 of hexane extract of stem-bark extracts of $V$. camporum out of $100 \mathrm{~g}$ of the sample will function as ascorbic acid.

Generally, TAC increased with increasing concentration. The higher the TAC, the better the activity of the sample. Although methanol extract showed slightly higher antioxidant activity than the hexane, both extracts demonstrated appreciable antioxidant activities. The experimental results of this assay prove that the stem-bark of $V$. camporum contains significant antioxidant therapeutic compounds and hence the need to exploit those compounds for future research. 
TABle 5: Total antioxidant capacity of methanol and hexane extracts expressed as gAAE/100 g.

\begin{tabular}{lc}
\hline Sample & TAC $(\mathrm{gAAE} / 100 \mathrm{~g})$ \\
\hline Methanol extract & $31.592 \pm 1.682$ \\
Hexane extract & $30.232 \pm 0.445$ \\
\hline
\end{tabular}

TAC: total antioxidant capacity; AAE: ascorbic acid equivalent.

3.6. Antimicrobial Activity of the Stem-Bark of V. camporum Extracts. Agar well diffusion and Broth microdilution methods were used to analyze the efficacy of the extracts as antimicrobial agents.

3.6.1. Agar Well Diffusion Method. The antimicrobial activities of the extracts (methanol and hexane) of the stembark of $V$. camporum were determined at three concentrations levels of $6.25,12.5$, and 25.0 with $0.05 \mathrm{mg} / \mathrm{mL}$ for reference drugs. The activity produced by the extracts and the reference drugs is presented in Table 6.

The agar well diffusion technique simply classifies microbes as susceptible, intermediate, or resistant, and it is broadly used to evaluate the antimicrobial activity of plant extracts [49]. The zone of inhibition estimates the minimum antimicrobial agent (plant extract) concentration adequate to inhibit microbial growth. The higher the zone of growth inhibition, the more susceptible the organisms to the extract or standard drug, and the more potent the antimicrobial activity of the extract/standard drug [17]. The sizes of the zone of inhibition are compared to standards to determine if the microorganism is sensitive or resistant to the plant extract. The results obtained from the experiment showed that the extracts of the stem-bark of $V$. camporum were effective and capable of inhibiting the growth of the selected microorganism employed for the assay with variable activity. The methanol and hexane extracts of the stem-bark of $V$. camporum exhibited variable antimicrobial activity against both Gram-positive and Gram-negative, and the test fungus within the concentration range of 6.25 to $25.0 \mathrm{mg} / \mathrm{mL}$ with zones of growth inhibition ranging from $10.0 \pm 0.128$ to $27.0 \pm 0.019 \mathrm{~mm}$. The lowest concentration, at which the methanol and hexane extracts recorded a zone of inhibition, was 6.25 and $12.5 \mathrm{mg} / \mathrm{mL}$, respectively. Even though all the test microorganisms were susceptible to the methanol extract at a concentration range of 6.25 to $25.0 \mathrm{mg} / \mathrm{mL}$, E. coli was the most susceptible, with $C$. albicans being the least susceptible at the highest concentration of $25.0 \mathrm{mg} / \mathrm{mL}$. However, $P$. aeruginosa was the most susceptible at lower concentrations of 6.25 and $12.5 \mathrm{mg} / \mathrm{mL}$. E. coli was the most susceptible to the hexane extract with $B$. subtilis being the least susceptible at the highest concentration of $25.0 \mathrm{mg} / \mathrm{mL}$. C. albicans was the most susceptible at lower concentration of $12.5 \mathrm{mg} / \mathrm{mL}$. The methanol extract showed inhibition against $P$. aeruginosa and $B$. subtilis at a concentration of $6.25 \mathrm{mg} / \mathrm{mL}$ but no inhibition against E. coli, S. aureus, and C. albicans. All the four test bacteria were susceptible to ciprofloxacin (standard drug), with S. aureus showing the highest susceptibility. Both extracts and clotrimazole (standard drug) showed activity against the fungus,
C. albicans. The extracts of the stem-bark of $V$. camporum were potentially effective against the test pathogenic microbes. Due to the significant activity of the extracts against the selected pathogenic microbes, further experiment was conducted to evaluate the minimum inhibitory concentration against tested microbes employed in this method.

3.6.2. Broth Microdilution. The methanol and hexane extracts of the stem-bark of $V$. camporum showed varying inhibitory activity against the test organisms as depicted in Table 7.

The MIC results showed that the stem-bark extracts of $V$. camporum exhibited varying inhibitory effects against the five selected microorganisms (two Gram-positive, two Gram-negative, and one fungus). The minimum inhibitory concentrations (MICs) were between the ranges of 0.1953 and $25.0 \mathrm{mg} / \mathrm{mL}$. The methanol extract showed the highest inhibitory activity against $E$. coli and B. subtilis with MIC of $0.1953 \mathrm{mg} / \mathrm{mL}$, whilst the hexane extract against E. coli, S. aureus, B. subtilis, and C. albicans at $12.5 \mathrm{mg} / \mathrm{mL}$. The lowest inhibitory activity of the hexane extract was observed against $P$. aeruginosa at $25.0 \mathrm{mg} / \mathrm{mL}$. The antimicrobial activity shown by the extracts could be attributed to the presence of secondary metabolites like terpenoids, tannins, saponins in both extracts, and alkaloids, phenols, flavonoids, and coumarins, which were found only in the methanol extract of $V$. camporum reported to have shown antimicrobial inhibitory activity [43]. Therefore, the antimicrobial activity exhibited by the methanol extracts of stem-bark of $V$. camporum against test organisms may support the ethnomedicinal use of boiling both the leaves and stem-bark as medication for the treatment of infections, skin rashes, mouth sores, pains, and boils.

3.7. Thin Layer Chromatography (TLC). The analytical TLC method was used to determine the number of components present in the extracts. The separated chromatographic spots, which were representative of compounds in the various extracts, were observed, and their $R_{f}$ values were determined as shown in Table 8 .

The methanol and hexane extracts of $V$. camporum showed four and six distinct spots with $R_{f}$ values ranging from 0.261 to 0.547 and 0.286 to 0.976 , respectively. The number of spots indicating the separated components in both the methanol and hexane extracts of $V$. camporum was fewer when compared to the phytochemicals identified to be present in each stem-bark extract with the mobile phase of ethyl acetate/hexane $(1: 4)$. This implies that some of the components did not elute or coeluted on the TLC plate because of the use of less polar solvent system as the mobile phase. It may be necessary to employ two-dimensional TLC, column chromatography, or high-pressure liquid chromatography (HPLC) to achieve complete separation of the components.

3.8. Column Chromatographic Separation. Column chromatography was employed to separate the less polar components of the methanol extracts of $V$. camporum. Four 
TABLE 6: Mean zones of inhibition (ZI) of methanol and hexane extracts of $V$. camporum and ciprofloxacin and clotrimazole standards.

\begin{tabular}{|c|c|c|c|c|c|c|}
\hline \multirow{2}{*}{ Sample/drug } & \multirow{2}{*}{ Conc. (mg/mL) } & \multicolumn{5}{|c|}{ Mean zone of inhibition $(\mathrm{mm})($ mean \pm SEM $)$} \\
\hline & & E. coli & S. aureus & P. aeruginosa & B. subtilis & C. albicans \\
\hline Ciprofloxacin & 0.05 & $24.0 \pm 0.121$ & $30.0 \pm 0.217$ & $28.0 \pm 0.081$ & $24.0 \pm 0.164$ & NA \\
\hline Clotrimazole & 0.05 & NA & NA & NA & NA & $22.0 \pm 0.171$ \\
\hline \multirow{3}{*}{ Methanol extract } & 25.00 & $27.0 \pm 0.019$ & $24.0 \pm 0.061$ & $22.0 \pm 0.099$ & $22.0 \pm 0.077$ & $20.0 \pm 0.184$ \\
\hline & 12.50 & $18.0 \pm 0.020$ & $16.0 \pm 0.090$ & $20.0 \pm 0.097$ & $16.0 \pm 0.068$ & $14.0 \pm 0.088$ \\
\hline & 6.25 & - & - & $14.0 \pm 0.186$ & $10.0 \pm 0.128$ & - \\
\hline \multirow{3}{*}{ Hexane extract } & 25.00 & $26.0 \pm 0.146$ & $18.0 \pm 0.119$ & $16.0 \pm 0.210$ & $14.0 \pm 0.114$ & $20.0 \pm 0.094$ \\
\hline & 12.50 & $14 \pm 0.024$ & $12.0 \pm 0.030$ & - & - & $16.0 \pm 0.171$ \\
\hline & 6.25 & - & - & - & - & - \\
\hline
\end{tabular}

NA: not applicable; diameter of the cork borer $=10 \mathrm{~mm}$.

Table 7: Minimum inhibitory concentrations (MICs) of the extracts of $V$. camporum and reference standard drugs against test organisms.

\begin{tabular}{lcccc}
\hline \multirow{2}{*}{$\begin{array}{l}\text { Test } \\
\text { organisms }\end{array}$} & \multicolumn{4}{c}{ Minimum inhibitory concentration $(\mathrm{mg} / \mathrm{mL})$} \\
& Methanol & Hexane & Ciprofloxacin & Clotrimazole \\
\hline E. coli & 0.1953 & 12.50 & $0.3906 \times 10^{-3}$ & NA \\
S. aureus & 0.3906 & 12.50 & $0.7813 \times 10^{-3}$ & NA \\
P. aeruginosa & 0.3906 & 25.00 & $3.125 \times 10^{-3}$ & NA \\
B. subtilis & 0.1953 & 12.50 & $3.125 \times 10^{-3}$ & NA \\
C. albicans & 0.3906 & 12.50 & NA & $1.563 \times 10^{-3}$ \\
\hline
\end{tabular}

NA: not applicable.

TABLE 8: Separated constituents of V. camporum extracts as determined using TLC.

\begin{tabular}{lcc}
\hline Components & \multicolumn{2}{c}{ Retardation factor, $R_{f}$} \\
& Methanol extract & Hexane extract \\
\hline A & 0.261 & - \\
B & 0.285 & 0.286 \\
C & - & 0.357 \\
D & 0.438 & - \\
E & 0.547 & 0.524 \\
F & - & 0.714 \\
G & - & 0.738 \\
H & - & 0.976 \\
\hline
\end{tabular}

fractions, namely, A to $\mathrm{D}$, were separated after elution with a gradient of solvents EtOAc/Hexane $(5: 45 ; 10: 40)$ as indicated in Table 9.

The column chromatography results confirm the analytical TLC results of the components based on their exact matching of the retardation factors. The fractions were monitored by means of TLC (eluent, Hexane/EtOAc $4: 1$ ). The separated fractions were further screened qualitatively to determine the type of phytochemicals present and further determine their functional groups using FTIR analysis.

3.9. Phytochemical Screening on Purified Fractions. The purified fractions obtained from column chromatographic separation were screened qualitatively to determine the type of phytoconstituents present to ascertain the various bioactive components in the methanol extracts of $V$. camporum (Table 10).
TABle 9: Chromatographic separation of the fractions of constituents of methanol extracts of $V$. camporum.

\begin{tabular}{lc}
\hline Components & Retardation factor, $R_{f}$ \\
\hline A & 0.547 \\
B & 0.438 \\
C & 0.285 \\
D & 0.261 \\
\hline
\end{tabular}

TABLE 10: Phytochemical screening result for collected fractions of methanol extracts of $V$. camporum.

\begin{tabular}{lc}
\hline Components & Phytochemical \\
\hline A & Steroid \\
B & Steroid \\
C & Steroid \\
D & Terpenoid \\
\hline
\end{tabular}

The phytochemical screening results showed that fractions $\mathrm{A}, \mathrm{B}$, and $\mathrm{C}$ are steroids, and $\mathrm{D}$ is a terpenoid. This result corroborates the earlier screening of the crude methanol extracts having some of the indicated phytochemicals. Ongoing research is on the separation of all the components present in the extracts that will lead to isolation, purification, identification, and bioactivity determination of each component. The presence of these identified secondary metabolites supports the fact that the stem-bark of $V$. camporum could be exploited as a therapeutic candidate for helminthic, bacterial/fungal infections, inflammatory diseases, and diseases associated with oxidative-stress. These results also give credence to the ethnomedicinal uses of the stem-bark of $V$. camporum against human ailments. The purified fractions were further analyzed using FTIR to determine the various functional groups present in each purified compound.

3.10. FTIR Analysis. FTIR analysis was performed on the purified components obtained from the methanol extract after column chromatographic separation. The results are presented in Figures 7-10 and Tables 11 and 12.

The wave numbers around $2923-2854 \mathrm{~cm}^{-1}, 1742 \mathrm{~cm}^{-1}$, $1459-1371 \mathrm{~cm}^{-1}$, and $1221-1050 \mathrm{~cm}^{-1}$ positions of the spectra are characteristic of aliphatic $\left(\mathrm{Csp}^{3}-\mathrm{H}\right)$ stretch, nonconjugated $\mathrm{C}=\mathrm{O}$ stretch, $\mathrm{C}-\mathrm{H}$ bend, and $\mathrm{C}-\mathrm{O} / \mathrm{C}-\mathrm{C}$ 


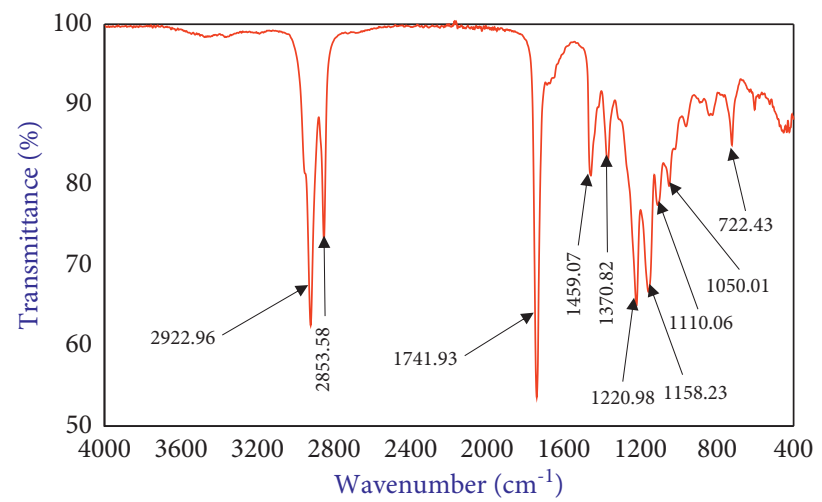

Figure 7: FTIR spectrum of fraction A from the methanol extract of V. camporum.

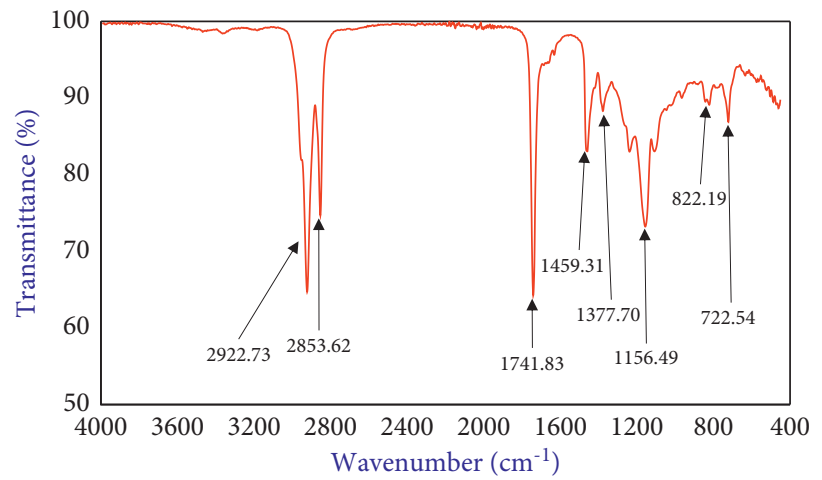

FIGURE 8: FTIR spectrum of fraction B from the methanol extract of $V$. camporum.

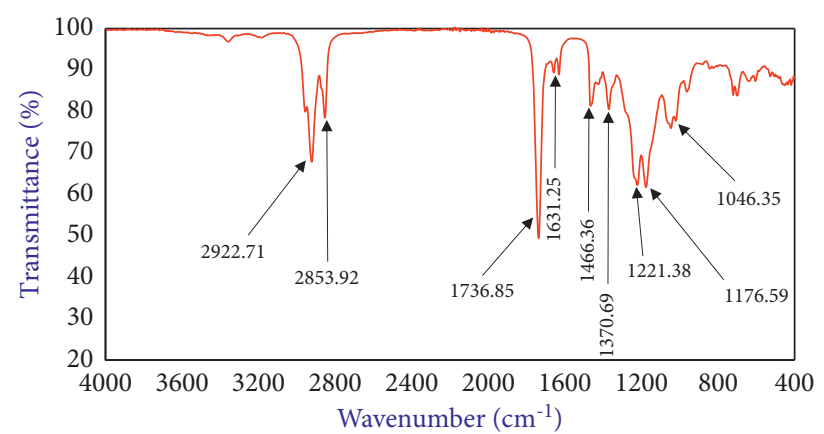

FIGURE 9: FTIR spectrum of fraction $C$ from the methanol extract of $V$. camporum.

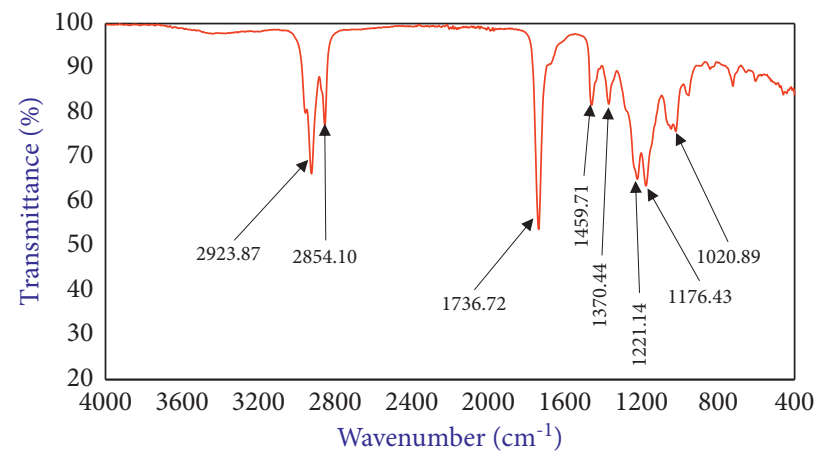

FIGURE 10: FTIR spectrum of fraction D from the methanol extract of $V$. camporum. 
TABLE 11: FTIR interpretation of purified fractions A and B from the methanol extract of V. camporum.

\begin{tabular}{|c|c|c|c|c|c|}
\hline \multicolumn{3}{|c|}{ Fraction A } & \multicolumn{3}{|c|}{ Fraction B } \\
\hline $\begin{array}{l}\text { Peak value } \\
\left(\mathrm{cm}^{-1}\right)\end{array}$ & Functional group & Inference & Peak value $\left(\mathrm{cm}^{-1}\right)$ & Functional group & Inference \\
\hline $\begin{array}{l}2923,2854 \\
1742 \\
1459,1371 \\
1221,1158 \\
1110,1050\end{array}$ & $\begin{array}{c}\mathrm{Csp}^{3}-\mathrm{H} \text { stretch } \\
\mathrm{C}=\mathrm{O} \text { stretch } \\
\text { C-H bend } \\
\text { C-O/C-C stretch }\end{array}$ & $\begin{array}{l}\text { The observed functional } \\
\text { groups confirm the presence } \\
\text { of steroid identified in the } \\
\text { screening test }\end{array}$ & $\begin{array}{c}2923,2854 \\
1742 \\
1459,1378 \\
1156\end{array}$ & $\begin{array}{l}\text { Csp }{ }^{3}-\mathrm{H} \text { stretch } \\
\mathrm{C}=\mathrm{O} \text { stretch } \\
\mathrm{C}-\mathrm{H} \text { bend } \\
\text { C-O stretch }\end{array}$ & $\begin{array}{l}\text { The observed functional } \\
\text { groups confirm the presence } \\
\text { of steroid identified in the } \\
\text { screening test }\end{array}$ \\
\hline
\end{tabular}

TABLE 12: FTIR interpretation of purified fractions $C$ and $D$ from the methanol extract of V. camporum.

\begin{tabular}{|c|c|c|c|c|c|}
\hline \multicolumn{3}{|c|}{ Fraction C } & \multicolumn{3}{|c|}{ Fraction D } \\
\hline $\begin{array}{l}\text { Peak value } \\
\left(\mathrm{cm}^{-1}\right)\end{array}$ & Functional group & Inference & Peak value $\left(\mathrm{cm}^{-1}\right)$ & Functional group & Inference \\
\hline $\begin{array}{l}2922,2854 \\
1737 \\
1631 \\
1466,1371 \\
1221,1177, \\
1045\end{array}$ & $\begin{array}{c}\mathrm{Csp}^{3}-\mathrm{H} \text { stretch } \\
\mathrm{C}=\mathrm{O} \text { stretch } \\
\mathrm{C}=\mathrm{C} \text { stretch } \\
\mathrm{C}-\mathrm{H} \text { bend } \\
\text { C-O/C-C stretch }\end{array}$ & $\begin{array}{l}\text { The observed functional groups } \\
\text { confirm the presence of } \\
\text { unsaturated steroid identified in } \\
\text { the screening test }\end{array}$ & $\begin{array}{c}2924,2854 \\
1737 \\
1460,1370 \\
1221,1176, \\
1021\end{array}$ & $\begin{array}{c}\text { Csp }^{3}-\mathrm{H} \text { stretch } \\
\mathrm{C}=\mathrm{O} \text { stretch } \\
\mathrm{C}-\mathrm{H} \text { bend } \\
\text { C-O/C-C } \\
\text { stretch }\end{array}$ & $\begin{array}{l}\text { The observed functional } \\
\text { groups confirm the presence } \\
\text { of terpenoid identified in the } \\
\text { screening test }\end{array}$ \\
\hline
\end{tabular}

stretching vibrational frequencies functional groups, respectively [71, 72]. These functional groups show that fractions A and B are highly saturated with nonconjugated carbonyl stretching frequencies typical of steroidal compound motifs. The major difference between the spectra of fractions $\mathrm{A}$ and $\mathrm{B}$ is in the fingerprint region around 1100 to $1200 \mathrm{~cm}^{-1}$. Spectrum of fraction A has doublet medium peaks, while B has a singlet (with triplet shoulder spike) around the fingerprint region. Steroids generally possess aliphatic groups (i.e., C-H) in the ring system and on the side chain and may also possess one or more carbonyl $(\mathrm{C}=\mathrm{O})$ and or ethylenic groups $(C=\mathrm{C})$. The presence of these functional groups in the purified fractions $\mathrm{A}$ and $\mathrm{B}$ confirms the presence of steroids as identified from the phytochemical analysis.

The FTIR spectrum of fraction $\mathrm{C}$ indicated the presence of aliphatic saturated $\mathrm{Csp}^{3}-\mathrm{H}$ stretch $\left(2854-2922 \mathrm{~cm}^{-1}\right)$, carbonyl $\mathrm{C}=\mathrm{O}$ stretch $\left(1737 \mathrm{~cm}^{-1}\right)$, olefinic double bond, $\mathrm{C}=\mathrm{C}$ stretch $\left(1631 \mathrm{~cm}^{-1}\right), \mathrm{C}-\mathrm{H}$ bending $\left(1370-1466 \mathrm{~cm}^{-1}\right)$, and $\mathrm{C}-\mathrm{O}$ stretch $\left(1145-1221 \mathrm{~cm}^{-1}\right)$ wave numbers typical of unsaturated steroidal structural backbone. The functional groups in the spectrum of the purified fraction $\mathrm{C}$ confirm the presence of unsaturated steroid as identified from the phytochemical analysis.

The FTIR spectrum of fraction D showed the presence of aliphatic saturated $\mathrm{Csp}^{3}-\mathrm{H}$ stretch $\left(2853-2924 \mathrm{~cm}^{-1}\right)$, carbonyl $\mathrm{C}=\mathrm{O}$ stretch $\left(1737 \mathrm{~cm}^{-1}\right), \mathrm{C}-\mathrm{H}$ bending $\left(1370-1460 \mathrm{~cm}^{-1}\right)$, and C-O stretch (1021-1221 $\mathrm{cm}^{-1}$ ) absorption frequencies [72]. The presence of these functional groups in the purified fraction D confirms the presence of saturated terpenoid as identified from the phytochemical analysis.

The FTIR analysis of all the fractions A, B, C, and D confirms the identified secondary metabolites steroids and terpenoids, respectively from the screening test. Further structural identification and elucidation is ongoing in our research laboratory.

\section{Conclusion}

The methanol and hexane extracts of $V$. camporum showed the presence of secondary metabolites including alkaloids, phenols, tannins, saponins, terpenoids, flavonoids, steroids, phytosterols, proteins, and amino acids, phlobatannins, glycosides, cardiac glycosides, coumarins, and anthocyanins. This study has demonstrated that extracts of the stem-bark of $V$. camporum exhibit considerable antioxidant, antimicrobial, anti-inflammatory, and anthelminthic activities. The biological activities of the extracts were observed to be higher in the methanol compared to the hexane extract. This study has provided some justification for the folkloric use of the stem-bark of this medicinal plant for the treatment of mouth sores, pains, inflammation, and skin rashes. Further studies on isolation, characterization, identification, and determination of biological activities of the isolates from the stem-bark of $V$. camporum are ongoing in our research laboratory.

\section{Data Availability}

The data used to support the findings of this study are included within the article.

\section{Disclosure}

Part of this work was presented as a poster at the Research Seminar and Poster Presentation held at the Department of Chemistry, Kwame Nkrumah University of Science and Technology, Kumasi, Ghana, in March 2020.

\section{Conflicts of Interest}

The authors declare that there are no conflicts of interest regarding the publication of this paper. 


\section{Acknowledgments}

The authors are very appreciative to the Departments of Chemistry and Pharmaceutical Microbiology as well as the Central Laboratory of KNUST for the use of their facilities for this study. The authors acknowledge Mr. Clifford Osafo Asare and Mr. Lawrence Yeboah of the Department of Herbal Medicine and Theoretical and Applied Biology, KNUST, for the technical support.

\section{References}

[1] C. Osei Akoto, A. Acheampong, Y. D. Boakye, B. Kokloku, and G. Kwarteng, "In vitro anthelmintic, anti-inflammatory, antioxidant activities and FTIR analysis of Sclerocarya birrea root," Journal of Pharmacognosy and Phytochemistry, vol. 9, no. 2, pp. 1389-1401, 2020.

[2] R. H. Patil, M. P. Patil, and V. L. Maheshwari, "Bioactive secondary metabolites from endophytic fungi," Studies in Natural Products Chemistry, vol. 49, pp. 189-205, 2016.

[3] N. Thomford, D. Senthebane, A. Rowe et al., "Natural products for drug discovery in the 21st century: innovations for novel drug discovery," International Journal of Molecular Sciences, vol. 19, no. 6, p. 1578, 2018.

[4] A. Harvey, "Natural products in drug discovery," Drug Discovery Today, vol. 13, no. 19-20, pp. 894-901, 2008.

[5] P. Cheuka, G. Mayoka, P. Mutai, and K. Chibale, "The role of natural products in drug discovery and development against neglected tropical diseases," Molecules, vol. 22, no. 1, p. 58, 2017.

[6] D. J. Newman and G. M. Cragg, "Natural products as sources of new drugs from 1981 to 2014," Journal of Natural Products, vol. 79, no. 3, pp. 629-661, 2016.

[7] D. J. Newman and G. M. Cragg, "Natural products as sources of new drugs over the last 25 Years $\perp$," Journal of Natural Products, vol. 70, no. 3, pp. 461-477, 2007.

[8] A. Butler and J. N. Carter-franklin, "The role of vanadium bromoperoxidase in the biosynthesis of halogenated marine natural products," Natural Product Reports, vol. 21, no. 1, pp. 180-188, 2004.

[9] S. Bernardini, A. Tiezzi, V. Laghezza Masci, and E. Ovidi, "Natural products for human health: an historical overview of the drug discovery approaches," Natural Product Research, vol. 32, no. 16, pp. 1926-1950, 2018.

[10] P. S. Tresina, M. S. Selvam, A. Rajesh, A. Doss, and V. R. Mohan, "Natural products in drug discovery: approaches and development," Journal of Pharmaceutical Research International, vol. 33, no. 35A, pp. 93-110, 2021.

[11] C. Osei Akoto, A. Acheampong, Y. D. Boakye, S. Takyi, and R. Garba, "Phytochemical screening and in vitro antioxidant and antimicrobial activities of the extracts of the stem-bark of Psydrax peruviana," Journal of Medicinal Plants Studies, vol. 7, no. 5, pp. 28-34, 2019.

[12] U. Anand, N. Jacobo-herrera, A. Altemimi, and N. Lakhssassi, "A comprehensive review on medicinal plants as antimicrobial therapeutics: potential avenues of biocompatible drug discovery," Metabolites, vol. 9, no. 11, p. 258, 2019.

[13] M. S. Ahmad, A. Shawky, M. O. Ghobashy, and R. H. A. Felifel, "Effect of some medicinal plants on life cycle of citrus Brown mites (eutetranychusorientalis)," International Journal of Pharmaceutical Research and Allied Sciences, vol. 7, no. 4, pp. 13-17, 2018.
[14] K. N. Puro, M. U. Mazumder, P. Khazeo, R. Jyrwa, N. Jamir, and L. Sailo, "Qualitative and quantitative analysis of phytochemicals of crude extracts of Ageratum conyzoides L. leaves," Journal of Advanced Engineering Research, vol. 178, pp. 164-168, 2018.

[15] A. I. Kuruppu, P. Paranagama, and C. L. Goonasekara, "Medicinal plants commonly used against cancer in traditional medicine formulae in Sri Lanka," Saudi Pharmaceutical Journal, vol. 27, no. 4, pp. 565-573, 2019.

[16] C. Egbuna, S. M. Ezzat, H. Tijjani, and V. K. Srivastav, "Synthetic analogs of phytochemicals," Phytochemistry: An insilico and in-Vitro Update, pp. 23-55, 2019.

[17] C. Osei Akoto, A. Acheampong, Y. D. Boakye, D. Akwata, and M. Okine, "In vitro anthelminthic, antimicrobial and antioxidant activities and FTIR analysis of extracts of Alchornea cordifolia leaves," Journal of Pharmacognosy and Phytochemistry, vol. 8, no. 4, pp. 2432-2442, 2019.

[18] O. Osukoya, A. Fadaka, A. Fadaka et al., "In vitro anthelmintic and antioxidant activities of the leaf extracts of Theobroma cacao L," AIMS Agriculture and Food, vol. 4, no. 3, pp. 568-577, 2019.

[19] W. Khan, S. Subhan, D. F. Shams et al., "Antioxidant potential, phytochemicals composition, and metal contents of datura alba," BioMed Research International, vol. 2019, Article ID 2403718, 8 pages, 2019.

[20] S. C. Keeley and S. B. Jones, "Distribution of pollen types in Vernonia (Vernonieae: compositae)," Systematic Botany, vol. 4, no. 3, pp. 195-202, 1979.

[21] S. C. Keeley, J. T. Cantley, and T. J. Gallaher, "The "evil tribe" spreads across the land: a dated molecular phylogeny provides insight into dispersal, expansion, and biogeographic relationships within one of the largest tribes of the sunflower family (Vernonieae: compositae)," American Journal of Botany, vol. 108, no. 3, pp. 505-519, 2021.

[22] P. Erasto, D. S. Grierson, and A. J. Afolayan, "Antioxidant constituents inVernonia amygdalina," Pharmaceutical Biology, vol. 45, no. 3, pp. 195-199, 2007.

[23] I. T. Oyeyemi, A. A. Akinlabi, A. Adewumi, A. O. Aleshinloye, and O. T. Oyeyemi, "Vernonia amygdalina: a folkloric herb with anthelminthic properties," Beni-Suef University Journal of Basic and Applied Sciences, vol. 7, no. 1, pp. 43-49, 2018.

[24] D.-B. Asante, I. T. Henneh, D. O. Acheampong et al., "Antiinflammatory, anti-nociceptive and antipyretic activity of young and old leaves of Vernonia amygdalina," Biomedicine \& Pharmacotherapy, vol. 111, pp. 1187-1203, 2019.

[25] A. J. Vlietinck, L. Van Hoof, J. Totté et al., "Screening of hundred Rwandese medicinal plants for antimicrobial and antiviral properties," Journal of Ethnopharmacology, vol. 46, no. 1, pp. 31-47, 1995.

[26] F. A. Hamill, S. Apio, N. K. Mubiru et al., "Traditional herbal drugs of southern Uganda, I," Journal of Ethnopharmacology, vol. 70, no. 3, pp. 281-300, 2000.

[27] L. Kambizi and A. J. Afolayan, "An ethnobotanical study of plants used for the treatment of sexually transmitted diseases (njovhera) in Guruve District, Zimbabwe," Journal of Ethnopharmacology, vol. 77, no. 5-9, pp. 5-9, 2001.

[28] S. F. Yusoff, F. F. Haron, M. Tengku Muda Mohamed et al., "Antifungal activity and phytochemical screening of Vernonia amygdalina extract against botrytis cinerea causing gray mold disease on tomato fruits," Biology, vol. 9, no. 9, pp. 286-314, 2020.

[29] J. O. Oladele, O. M. Oyeleke, O. T. Oladele, and M. Olaniyan, "Neuroprotective mechanism of Vernonia amygdalina in a rat 
model of neurodegenerative diseases," Toxicology Reports, vol. 7, pp. 1223-1232, 2020.

[30] D. E. Wedge, J. C. G. Galindo, and F. A. Maćas, "Fungicidal activity of natural and synthetic sesquiterpene lactone analogs," Phytochemistry, vol. 53, no. 7, pp. 747-757, 2000.

[31] G. N. K. Kumari, S. Masilamani, M. R. Ganesh, S. Aravind, and S. R. Sridhar, "Zaluzanin D. : a fungistatic sesquiterpene from Vernonia arborea," Fitoterapia, vol. 74, no. 3, pp. 479-482, 2003.

[32] F. R. Rodrigues, D. A. A. S. Bispo, H. N. Brandão, T. L. Soares, W. A. B. D. Almeida, and J. R. F. D. Santana, "The impact of medium composition and photosynthetically active radiation level on the initial in vitro growth and production of flavonoids of Vernonia condensata baker," Biocatalysis and Agricultural Biotechnology, vol. 18, Article ID 101063, 2019.

[33] S. M. Kupchan, R. J. Hemingway, A. Karim, and D. Werner, "Tumor inhibitors. XLVII. Vernodalin and vernomygdin, two new cytotoxic sesquiterpene lactones from Vernonia amygdalina del," Journal of Organic Chemistry, vol. 34, no. 12, pp. 3908-3911, 1969.

[34] M. Jisaka, H. Ohigashi, K. Takegawa et al., "Steroid glucosides from Vernonia amygdalina, a possible chimpanzee medicinal plant," Phytochemistry, vol. 34, no. 2, pp. 409-413, 1993.

[35] K. Koshimizu, H. Ohigashi, and M. A. Huffman, "Use of Vernonia amygdalina by wild chimpanzee: possible roles of its bitter and related constituents," Physiology \& Behavior, vol. 56, no. 6, pp. 1209-1216, 1994.

[36] H. Ohigashi, M. Jisaka, T. Takagaki et al., "Bitter principle and a related steroid glucoside from Vernonia amygdalina, a possible medicinal plant for wild chimpanzees," Agricultural \& Biological Chemistry, vol. 55, no. 4, pp. 1201-1203, 1991.

[37] M. Jisaka, H. Ohigashi, T. Takagaki et al., "Bitter steroid glucosides, vernoniosides A1, A2, and A3, and related B1 from a possible medicinal plant, Vernonia amygdalina, used by wild chimpanzees," Tetrahedron, vol. 48, no. 4, pp. 625-632, 1992.

[38] M. Jisaka, H. Ohigashi, K. Takegawa, M. A. Huffman, and K. Koshimizu, "Antitumoral and antimicrobial activities of bitter sesquiterpene lactones of Vernonia amygdalina, a possible medicinal plant used by wild chimpanzees," Bioscience, Biotechnology, and Biochemistry, vol. 57, no. 5, pp. 833-834, 1993.

[39] G. O. Igile, W. Oleszek, S. Burda, and M. Jurzysta, "Nutritional assessment of Vernonia amygdalina leaves in growing mice," Journal of Agricultural and Food Chemistry, vol. 43, no. 8, pp. 2162-2166, 1995.

[40] K. Tunasamy, N. Suryadevara, and T. Athimoolam, "Screening of Vernonia amygdalina leaf extracts for antioxidant and antimicrobial activity," Materials Today: Proceedings, vol. 16, pp. 1809-1818, 2019.

[41] C. Osei Akoto, A. Acheampong, Y. D. Boakye, A. A. Naazo, and D. H. Adomah, "Anti-inflammatory, antioxidant, and anthelmintic activities of ocimum basilicum," Fruits, vol. 2020, 9 pages, 2020.

[42] G. E. Trease and W. C. Evans, Trease and Evans' Pharmacognosy, Company Ltd., New York, NY, USA, 16th edition, 2009.

[43] C. S. Kumari, N. Yasmin, M. R. Hussain, and M. Babuselvam, "In vitro anti-inflammatory and anti-artheritic property of rhizopora mucronata leaves," International Journal of Pharma Sciences and Research, vol. 6, no. 3, pp. 482-485, 2015.

[44] E. O. Ajaiyeoba, P. A. Onocha, and O. T. Olarenwaju, "In vitro anthelmintic properties of buchholzia coriaceae and gynandropsis gynandra extracts," Pharmaceutical Biology, vol. 39, no. 3, pp. 217-220, 2001.
[45] C. Sánchez-Moreno, J. A. Larrauri, and F. Saura-Calixto, “A procedure to measure the antiradical efficiency of polyphenols," Journal of the Science of Food and Agriculture, vol. 76, no. 2, pp. 270-276, 1998.

[46] D. Mukhopadhyay, P. Dasgupta, D. Sinha Roy et al., "A sensitive in vitro spectrophotometric hydrogen peroxide scavenging assay using 1,10-phenanthroline," Free Radicals and Antioxidants, vol. 6, no. 1, pp. 124-132, 2016.

[47] P. Prieto, M. Pineda, and M. Aguilar, "Spectrophotometric quantitation of antioxidant capacity through the formation of a phosphomolybdenum complex: specific application to the determination of vitamin E," Analytical Biochemistry, vol. 269, no. 2, pp. 337-341, 1999.

[48] I. Wiegand, K. Hilpert, and R. E. W. Hancock, "Agar and broth dilution methods to determine the minimal inhibitory concentration (MIC) of antimicrobial substances," Nature Protocols, vol. 3, no. 2, pp. 163-175, 2008.

[49] C. Osei Akoto, A. Acheampong, P. D. Tagbor, and K. Bortey, "Determination of the antimicrobial and antioxidant activities of the leaf extracts of Griffonia simplicifolia," Journal of Pharmacognosy and Phytochemistry, vol. 9, no. 2, pp. 537-545, 2020.

[50] G. H. Konning, C. Agyare, and B. Ennison, "Antimicrobial activity of some medicinal plants from Ghana," Fitoterapia, vol. 75, no. 1, pp. 65-67, 2004.

[51] O. F. Kunle and H. O. Egharevba, "Preliminary studies on Vernonia ambigua: phytochemical and antimicrobial screening of the whole plant," Ethnobot. Leafl., vol. 13, pp. 1216-1221, 2009.

[52] M. I. Abdullahi, A. Uba, A. Yaro, O. Maxwell, A. J. Yusuf, and S. Kabir, "Phytochemical screening, acute toxicity study and evaluation of antidiabetic properties of the methanolic leaf extract of Vernonia glaberrima ( asteraceae )," Journal of Pharmaceutical, Chemical and Biological Sciences, vol. 3, no. 2, pp. 169-177, 2015.

[53] E. M. Ilondu, "Phytochemical composition and efficacy of ethanolic leaf extracts of some Vernonia species against two phytopathogenic fungi," Journal of Biopesticides, vol. 6, no. 2, pp. 165-172, 2013.

[54] M. Gupta, U. K. Mazumder, L. Manikandan, P. K. Haldar, S. Bhattacharya, and C. C. Kandar, "Antibacterial activity of Vernonia cinerea,” Fitoterapia, vol. 74, no. 2, pp. 148-150, 2003.

[55] D. A. Akinpelu, "Antimicrobial activity of Vernonia amygdalina leaves,” Fitoterapia, vol. 70, no. 4, pp. 432-434, 1999.

[56] G. Tian, U. Zhang, T. Zhang, F. Yang, and Y. Ito, "Separation of flavonoids from the seeds of Vernonia anthelmintica Willd by high-speed counter-current chromatography," Journal of Chromatography A, vol. 1049, no. 1-2, pp. 219-222, 2004.

[57] A. O. Ogundare, F. C. Adetuyi, and F. A. Akinyosoye, "Antimicrobial activities of Vernonia tenoreana," African Journal of Biotechnology, vol. 5, no. 18, pp. 1663-1668, 2006.

[58] N. J. Toyang, E. N. Ateh, J. Keiser et al., "Toxicity, antimicrobial and anthelmintic activities of Vernonia guineensis Benth. (Asteraceae) crude extracts," Journal of Ethnopharmacology, vol. 144, no. 3, pp. 700-704, 2012.

[59] T. Rabe, D. Mullholland, and J. Van Staden, "Isolation and identification of antibacterial compounds from Vernonia colorata leaves," Journal of Ethnopharmacology, vol. 80, no. 1, pp. 91-94, 2002.

[60] S. M. F. Bessada, J. C. M. Barreira, and M. B. P. P. Oliveira, "Asteraceae species with most prominent bioactivity and their potential applications: a review," Industrial Crops and Products, vol. 76, pp. 604-615, 2015. 
[61] C. B. I. Alawa, A. M. Adamu, J. O. Gefu et al., "In vitro screening of two Nigerian medicinal plants (Vernonia amygdalina and Annona senegalensis) for anthelmintic activity," Veterinary Parasitology, vol. 113, no. 1, pp. 73-81, 2003.

[62] N. J. Toyang and R. Verpoorte, "A review of the medicinal potentials of plants of the genus Vernonia (Asteraceae)," Journal of Ethnopharmacology, vol. 146, no. 3, pp. 681-723, 2013.

[63] E. O. Farombi and O. Owoeye, "Antioxidative and chemopreventive properties of Vernonia amygdalina and Garcinia biflavonoid," International Journal of Environmental Research and Public Health, vol. 8, no. 6, pp. 2533-2555, 2011.

[64] B. A. Iwalokun, B. U. Efedede, J. A. Alabi-Sofunde, T. Oduala, O. A. Magbagbeola, and A. I. Akinwande, "Hepatoprotective and antioxidant activities of Vernonia amygdalinaon acetaminophen-induced hepatic damage in mice," Journal of Medicinal Food, vol. 9, no. 4, pp. 524-530, 2006.

[65] F. Zhu, B. Du, and B. Xu, "Anti-inflammatory effects of phytochemicals from fruits, vegetables, and food legumes: a review," Critical Reviews in Food Science and Nutrition, vol. 58, no. 8, pp. 1260-1270, 2018.

[66] K. B. Ishnava and P. S. Konar, "In vitro anthelmintic activity and phytochemical characterization of Corallocarpus epigaeus (Rottler) Hook f. tuber from ethyl acetate extracts," Bulletin of the National Research Centre, vol. 44, no. 33, pp. 1-10, 2020.

[67] Y.-J. Zhang, R.-Y. Gan, S. Li et al., "Antioxidant phytochemicals for the prevention and treatment of chronic diseases," Molecules, vol. 20, no. 12, pp. 21138-21156, 2015.

[68] İ. Gülçin, Ö. İ. Küfrevioğlu, M. Oktay, and M. E. Büyükokuroğlu, "Antioxidant, antimicrobial, antiulcer and analgesic activities of nettle (Urtica dioica L.)," Journal of Ethnopharmacology, vol. 90, no. 2-3, pp. 205-215, 2004.

[69] K. Iqbal, A. Khan, and M. M. A. K. Khattak, "Biological significance of ascorbic acid (vitamin C) in human health-a review," Pakistan Journal of Nutrition, vol. 3, no. 1, pp. 5-13, 2004.

[70] N. Francenia Santos-Sánchez, R. Salas-Coronado, C. Villanueva-Cañongo, and B. Hernández-Carlos, "Antioxidant compounds and their antioxidant mechanism," Antioxidants, vol. 90, no. 2-3, pp. 205-215, 2019.

[71] C. Osei Akoto and J. D. Rainier, "Harnessing glycal-epoxide rearrangements: the generation of the $\mathrm{AB}, \mathrm{EF}$, and IJ rings of adriatoxin," Angewandte Chemie International Edition, vol. 47, no. 42, pp. 8055-8058, 2008.

[72] C. Osei Akoto and J. D. Rainier, "Concise seven-membered oxepene/oxepane synthesis-structural motifs in natural and synthetic products," Synthesis, vol. 51, no. 18, pp. 3529-3535, 2019. 